\title{
NORMAL COSTS AND DEMAND EFFECTS IN PRICE SETTING
}

\author{
A Study of Retailing \\ Bart NOOTEBOOM, Aad KLEIJWEG and Roy THURIK* \\ Research Institute for Small and Medium-Sized Business, 2701 AA Zoetermeer, The Netherlands
}

Received May 1986, final version received January 1987

\begin{abstract}
The study aims at contributing to the debate whether there are demand effects in models that seek to explain prices as mark-ups on costs. For costs it considers actual costs, normal costs and an intermediate model with a partial adjustment to the deviation of actual from normal costs. For demand effects it considers an effect on the price level of a change of demand, with an allowance for asymmetry between demand growth and demand decline. Tests and estimates are conducted on the basis of data from retailing.
\end{abstract}

\section{Introduction}

Price behaviour is a centre-piece of economic controversy. To the extent that prices are rigid, and do not respond to demand conditions, traditional price-auction equilibrium and its related advantage of automatic optimal efficiency do not obtain. ${ }^{1}$

There is general agreement that the price-auction view does approach reality in markets of primary goods (agricultural produce, raw materials). ${ }^{2}$ Reasons for this are their (often) inelastic supply, homogeneity and easily accessible information on volumes and prices. Concerning secondary goods (manufacturing products), however, there is widespread doubt. Reasons for this are the pervasiveness of monopolistic or oligopolistic elements, product differentiation and non-price competition, opportunities for excess capacity to make supply elastic, and opportunities for other goals of firms than traditional profit maximization.

The tertiary sector (commercial services) has received only limited attention in this context. That is hardly justifiable, since that sector, and especially retailing, is important for studies of welfare. As indicated by Andrews and Brunner (1975), traditional theory tends to integrate the different stages in

\footnotetext{
*We thank two anonymous referees for helpful comments on an earlier draft.

'Cl. Thurow (1984), Eichner (1979).

${ }^{2}$ Cf. Kalecki (1971), Eichner (1979), Wood (1975).
} 
the chain of manufacturing, wholesaling and retailing. as if firms incorporated the entire trajectory. But that is the exception rather than the rule, and between the different segments there are often considerable differences in market structure, type of process, type of customer and size and behaviour of firms.

In the present article, a model of retail margins presented in Nooteboom $(1980,1985)$ is discussed in the context of the debate on the effects of average costs, normal costs and demand conditions. Normal costs are defined as costs from which the effects of short-term demand fluctuations are eliminated. The emphasis is not on the possible merits of the model for studies of retailing, ${ }^{3}$ but on the merits that it might have in the wider context of studies to establish whether, and in what way, demand might affect prices after normal costs have been taken into account.

A special feature of the model is, that the price level is specified as a function of demand growth and the growth of market share of the class of firms whose price is to be explained. This represents a reversal with respect to traditional equilibrium theory, where price changes are specified as a function of the level of excess demand.

Another feature is that average firm size is also taken into account. Of course, all this hardly fits in with the traditional price-auction view of markets, but we do not consider that view very realistic anywhere outside markets of primary goods and, perhaps, financial markets.

The conclusion of the present study is that there is a partial adjustment of prices to the deviation of actual from normal costs and, in addition, an effect of demand growth.

\section{Mark-up models}

Surveys of the literature on pricing have been provided by Nordhaus (1972) and Laidler and Parkin (1975), and will not be fully repeated here.

As formulated by Laidler and Parkin: 'Two questions have dominated the literature ... First: does excess demand exert an independent upward pressure on prices, particularly of manufacturers, or does its influence come entirely through its effect upon factor prices, particularly wages, and hence upon costs? Second: in as much as prices respond to cost changes, do they respond to changes in actual costs or to changes in some normalised or expected cost measure? ${ }^{4}$

According to traditional price-auction theory, prices adjust in proportion to excess demand until a set of prices has been found that clears the market

\footnotetext{
${ }^{3}$ For that we refer to Nooteboom $(1980,1985)$.

${ }^{4}$ Laidler and Parkin (1975, p. 766). In their micro mark-up model for individual retail firms, Bode, Koerts and Thurik (1986) discriminate between out of pocket costs and remaining costs, and conclude that remaining costs are not always passed on completely.
} 
at current demand and capacity. If equilibrium is maintained, prices adjust to marginal costs. If equilibrium does not obtain, we should see price changes in proportion to excess demand. In a mark-up model causality thus should proceed from the level of (excess) demand to a change of price.

In an early study that still retains its relevance, Hall and Hitch (1939) suggested that the majority of entrepreneurs apparently do not aim at a short-run maximization of profits, and establish their price by adding a margin on prime or direct costs per unit, to cover overheads, with a further 'conventional' addition for profit. This was based on a survey of businesses, mainly in manufacturing. In some cases, however, businessmen worked backwards from some 'given' price, established by tradition, convenience, acceptance by customers or price setting by a price leader, and improved efficiency or adjusted the quality of the product until full cost equalled that price. This principle, named the 'price-minus principle of cost', was later picked up by Smyth (1967). Wood (1975) developed a theory of profits on the assumption that businessmen seek maximal growth of sales rather than maximal profits, and thereby prefer retained profits as a source of finance (or are restricted to that source in their relation to banks and shareholders) for investment, and thus set prices, within restrictions, so as to generate funds for future investments. Woods analysis also shows that they take into account the possible effect of prices on sales.

Laidler and Parkin (1975) reported a number of empirical studies in which, in addition to factor price changes, excess demand was found to play a role in explaining price changes, on the basis of a variety of excess demand variables. In a more recent study, Maccini (1978) found that demand factors perform at least as well as expected prices in the explanation of prices in manufacturing. As reported by Laidler and Parkin, the results led to a consensus that 'excess demand exerted an upward pressure on prices independently of changes in factor prices and hence costs'. ${ }^{5}$ They also reported that this consensus was challenged by Godley and Nordhaus (1972), who advanced the 'normal cost' hypothesis, according to which prices respond to changes in 'normal' costs, and are independent of excess demand. Before Godley and Nordhaus, a normal cost model had been used by Neild (1963), who also found no demand effects after taking normal costs into account. Here, the 'normal' value of a variable is defined as the value it would take, other things being equal, if output were on its trend path. ${ }^{6}$ By taking away cyclical effects in factor prices and productivity they computed a time series of normal costs. If price is taken as a mark-up on those costs, no demand effects were found.

Laidler and Parkin criticised the study for specifying price changes as a function of changes in excess demand, while according to the price-auction

\footnotetext{
${ }^{5}$ Laidler and Parkin (1975, p. 767).

${ }^{6}$ Godley and Nordhaus (1972, p. 854).
} 
view price changes are a function of the level of (excess) demand. McCallum (1970) had extended the same criticism to Rushdy and Lund (1967). He argues that if the price level is specified to depend on the level of (excess) demand, this 'would imply that a non-zero level of excess demand which remained constant period after period would not induce, ceteris faribus, a change in the price level. The "Law of Supply and Demand" would not be in force'? Coutts, Godley and Nordhaus (1978) rejected this criticism on the grounds that traditional theory cannot be assumed to represent actual firm behaviour, and that price change as a function of the level of demand would implausibly imply that 'prices would rise relative to costs indefinitely so long as capacity utilization is high, and even less plausibly, that prices will fall forever relative to costs ... if output is at all below, though not falling relative to, trend. ${ }^{8}$ Nevertheless, in their revised and more extensive study they included tests of an effect of the level of demand on price changes, lagged and non-lagged, and found none to speak of. The conclusions were again restricted to manufacturing, with the acknowledgement that in the case of primary products the situation is different.

The fact that in previous studies demand effects were found was explained by Coutts, Godley and Nordhaus in the following manner. During a shortterm upswing of demand, total unit costs will be relatively low due to a high level of capacity utilization, at which fixed costs are spread over a larger volume of sales. During a short-term downswing of demand, the reverse applies. Hence, in a mark-up model on the basis of short-term full costs per unit including cyclical effects, demand will be found to have an effect, but only because of the cyclical effects. The effect disappears if one takes normal costs as the basis for the mark-up. Actually, prices are set on the basis of normal costs without regard to demand.

As noted by Laidler and Parkin this yields a 'fundamental difficulty in identifying the separate effects of actual cost changes, "normal" cost changes and excess demand. When actual costs are combined with excess demand both variables are significant; the use of "normal" costs necessarily leaves a smaller role for excess demand to play'. This was recognized by Coutts, Godley and Nordhaus, who granted that the results we are about to present are conditional on the normal price hypothesis, and on the way that the hypothesis has been embodied in critical assumptions relating to normalization, choice of variables, and so forth ... We cannot say that we are testing other price hypotheses; we are simply testing for the presence of demand in a normal cost mark-up. ${ }^{10}$

\footnotetext{
${ }^{7}$ McCallum (1970, p. 149).

${ }^{8}$ Coutts, Godley and Nordhaus (1978, p. 65).

${ }^{9}$ Laidler and Parkin (1975, p.768).

${ }^{10}$ Coutts, Godley and Nordhaus (1978, p. 63-64).
} 
In view of this difficulty, it may be that the choice of model is a matter of theoretical plausibility, or direct tests of firm behaviour, rather than statistical tests of implications from mark-up models. What is more plausible; that businessmen set prices on the basis of short-term actual costs, but with an eye on demand; or on the basis of normal costs without regard to short-term developments of demand? Perhaps we have to go back to the methodology used by Hall and Hitch, to decide on the issue by interviewing businessmen.

Like Smyth (1967), ${ }^{11}$ we are wary of the static character of full-cost principles, including the normal cost principle. As recognized in marketing, markets in general appear to be too dynamic for such a view. As formulated by Smyth: "in marketing there is an abhorrence of equilibrium, emphasis is constantly placed on the disruption of established routines'. ${ }^{12}$

Summing up, the following seems plausible. Prices are set on the basis of average full unit costs, including an allowance for fixed costs and for profit. This may be done individually, or by a price leader followed by the majority of remaining firms. The profit margin may be set so as to generate internal funds for investment. A certain degree of price stability is sought after, whereby mark-ups are not adjusted instantaneously to every minute vagary of demand. However, for many small businesses anything as sophisticated as normal costs, with a systematic decycling of actual costs, does not seem feasible, though this will depend on the sophistication of the businessmen concerned. Furthermore, in most markets businessmen are likely to be on the lookout for signs of relatively favourable or unfavourable developments in market position (market share) and total demand. The extent, speed and time-horizon of adjustments to market position and total demand are likely to depend on a number of characteristics, such as: inventory turnover, intensity of price competition, ease of entry, size of firms, sophistication and objectives of businessmen. A further question is what kind of market signals businessmen keep in sight for their decisions on prices. We suggest that an important one is market share. Concerning total market demand, it might be the level of demand which affects the price level, but it might also be the rate of change of demand, once we step away from the traditional price-auction view. This brings us to our own mark-up model.

\section{A mark-up model of retail margins}

The determination of retail margins, interpreted as prices of retail services, has received scant attention in the economic literature. In the literature on retailing and marketing considerable attention has been paid to price leadership, the widespread uniformity of retail margins within types of trade, the large share of fixed costs that can only arbitrarily be attributed to

"Smyth (1967, p. 113).

${ }^{12}$ Smyth (1967, p. 117). 
individual goods on sale, price awareness and shop selection on the part of consumers, the practice of using certain products as 'loss-leaders', problems of discrimination with respect to purchase prices, partial spatial monopolies and the effects of resale price maintenance and its abolition. ${ }^{13}$

Cyert and March (1963) offer an intensive study of price determination on the micro level of one department in a large department store. Economic theories and models that explain average margins by type of trade, on the basis of costs and demand conditions, are rare. Smyth (1967) points to the self-service revolution in retailing and the demise of resale price maintenance, which transformed retailing from a cost-plus to a price-minus sector of the economy:. ${ }^{14}$ Nooteboom (1985) presents a model for an explanation of average percentage gross margin (p.g.m.) per type of shop, ${ }^{15}$ in both crosssection and time series studies. P.g.m. (defined as realized sales minus cost of purchase, as a percentage of sales) is explained as a mark-up on average (actual) percentage operating costs excluding a reward for shopkeepers' labour (as a percentage of sales). The mark-up is additively composed of four elements. They represent:

- some average reward for shopkeepers' labour, divided by average sales per shop (in the shop type considered). This term implies that, ceteris paribus, an increasing scale, in the sense of an increasing average shop size, squeezes the percentage mark-up. The average reward for shopkeepers' labour was estimated endogenously;

- the demand elasticity of the product/service package offered (in the type of shop considered), as a proxy for the luxury level of the package. The rationale is that, for a higher luxury level, consumer dependence on the retailer is greater, whereby there are more opportunities for higher profits, while turnover of sales is lower, whereby a given target return on investment requires a higher net profit per unit of sale;

- a 'life-cycle-effect' in the form of the change of market share of the shop type (with respect to other suppliers of products sold by the shop type). The rationale is that during the penetration phase of the shop type there are opportunities for above-normal profits, while in the phase of decline profits are squeezed to below-normal levels in the attempt to stop or slow further decline of market share. 'Normal' level is defined as the level associated with constant market share;

- a demand effect in the form of the percentage (volume) change of total consumer spending on goods provided by the shop type. The underlying hypothesis is that retailers generally seek growth of sales. As a result, if

\footnotetext{
${ }^{13} \mathrm{Cr}$., for example, McClelland (1963, 1966), Holdren (1960), Bucklin (1972), Dreesman (1963), Palamountain (1955), Nooteboom (1980), Nyström (1970), Tucker and Yamey (1973).

${ }^{14}$ Smyth $(1967$, p. 117).

15'Type of shop' is a class of shops that are similar with respect to product-service package, extent of own production, etc.
} 
total demand declines, maintaining sales requires a larger market share, which is pursued by means of a tighter margin. This is likely to be initiated by a market leader, and others feel forced to follow suit. If the effect is symmetrical, an increase of demand has the reverse effect: market share is less essential, and the margin is widened to pursue profits while the going is good'.

In mathematical terms, the full model is specified as follows:

$$
\mu_{i t}=\kappa_{i t}+\frac{w_{t}}{q_{i t}}+\alpha_{3} e_{i t}+\alpha_{4} \Delta M_{i t}+\alpha_{5} \dot{c}_{i t}
$$

and will be estimated in the following form:

$$
\mu_{i t}=\alpha_{1} \kappa_{i t}+\frac{\alpha_{2}}{q_{i t}}+\alpha_{3} e_{i t}+\alpha_{4} \Delta M_{i t}+\alpha_{5} \dot{c}_{i t}+u_{i t}
$$

where

$i=$ index of the shop type,

$t=$ index of the year,

$\mu \quad=$ gross margin $(\%)$,

$\kappa=$ total costs excluding a reward for shopkeepers' labour $(\%)$,

$w$ =some average reward for shopkeepers' labour (at constant price),

$q \quad=$ average sales size per shop (at constant prices),

$e \quad=$ income elasticity of demand for the product-service package, $\Delta M_{i r}=M_{i t}-M_{i r-1}$, where $M=$ market share,

$\dot{c} \quad=$ percentage change of the volume of total demand for the products sold,

$u \quad=$ stochastic disturbance term.

Note that since $w_{1}$ is unknown, it will be estimated as a coefficient $\left(\alpha_{2}\right)$ in the model, and that a coefficient is appended to percentage costs; its deviation from one will be tested.

This model has been used in various studies in the retail and the hotel and catering sector. ${ }^{16}$ In the present study data are used for 16 shop types of independents, in Dutch retailing, for the period 1976-1983, with a total of 128 observations. This is the same data set as used in Nooteboom and Thurik (1985), but with the year 1983 added. No complete data are available on market share changes, so that this variable has to be dropped. If the sample of shop types is sufficiently wide, this will not bias the coefficients,

\footnotetext{
${ }^{16}$ For retailing, see Nooteboom $(1980,1985)$, Nooteboom and Thurik (1985) and Nooteboom, Thurik and Vollebregt (1987). For the hotel and catering sector, see van der Hoeven and Thurik (1987).
} 
since then average market share changes can be expected to be zero (one shop type's gain is the other's loss). It could not be checked, however, whether the sample is adequate in this sense. The data all refer to small enterprises, and it is possible, and indeed likely, that they have systematically lost market share to large retailing business, so that the risk of bias cannot be excluded. In particular, it is known that a persistent market share decline occurs for the independent general food trade ('grocers'). For this reason we add a dummy variable for this type of trade. We expect it to yield a negative coefficient, due to the decline of market share. We also allow for a remainder in the form of a constant term, to pick up effects not accounted for.

The first step is to estimate the margin model according to (1). In the model we used the average value of inventory as a percentage of sales instead of the demand elasticity variable, since it is difficult to measure the elasticity. The underlying idea is that when in a shop type the level of inventory relative to sales is high, and hence inventory turnover is relatively low, one needs a higher net profit per unit of sales to achieve a given target return on capital (embodied in both inventory and shop space). We also allowed for an asymmetry between the effects of demand growth and demand decline, because behaviour may not be symmetrical. For example, Hall and Hitch (1939) stated that 'a few (firms) ... might charge more in a period of exceptionally high demand, and a greater number ... might charge less in periods of exceptionally depressed demand'. The result is as follows:

$$
\begin{aligned}
& \mu_{i t}=4.5+0.97 \kappa_{i t}+8.7\left(1 / q_{i t}\right)+7.8\left(V_{t i} / Q_{i t}\right)+0.067 \dot{c}_{i t}^{+} \\
& \begin{array}{lll}
(1.0)(0.03) \quad(1.5) \quad(1.1) \quad(0.025)
\end{array} \\
& +0.087 \dot{c}_{i t}^{-}-3.4 D_{g}, \quad R^{2}=0.980, \\
& (0.040) \quad(0.5)
\end{aligned}
$$

where $\mu$ (gross margin as a percentage of sales), $\kappa$ (operating costs excluding reward for shopkeepers' labour as a percentage of sales), $\dot{c}^{+}$(percentage change of demand, when growing), $\dot{c}^{-}$(percentage change of demand, when declining) are expressed in percentage points, $q$ (average sales per shop) is expressed in 1,000 Dfl. at 1976 prices, whereby its coefficient represents an implicit reward for shopkeepers' labour in $1,000 \mathrm{Dfl}$. at 1976 prices, $Q$ is average sales per shop in 1,000 Dfl. at current prices, and $V$ is average value of stock in 1,000 Dfl. at current prices; $D_{g}$ is a dummy variable for grocery and liquor shops. The figures in parentheses are standard errors.

As in previous studies, the coefficient of percentage costs is not significantly different from unity, in accordance with our theory. Unlike in previous studies, however, there is a significant remainder in the form of a constant term. For grocery and liquor shops $D_{g}=1$ and it cancels out. According to our interpretation (and the reasons for introducing the dummy variable) this 
is due to a declining market share. The positive constant term may reflect rising market shares in some other types of trade. As in previous studies the estimate of the average reward for shopkeepers' labour ( 8.7 thousand Dfl.) is not significantly different, at a $5 \%$ significance level, from the legal minimum wage for employees in the Netherlands. There is some evidence for asymmetry in the effect of demand growth: the coefficient is higher during decline than during growth, but the difference is not significant, and in both cases the effect is significantly different from zero.

The effect appears to be smaller than in Nooteboom (1985), where the coefficient for demand growth was about 0.12 (estimated over a period during which there was no decline of demand). As was recognized in Nooteboom (1985): 'price competition is particularly fierce in the grocery trade, and in other trades the intensification of price competition due to declining consumer expenditure may be less. ${ }^{17}$ However, in view of the standard errors in (2), there is no difference at a $5 \%$ significance level. To give some idea of the size of the effect let us suppose demand declines by $2 \frac{1}{2} \%$; then according to the results in (2), the gross margin will, ceteris paribus, be 0.2 percentage point less than it would have been at stable (zero growth) demand. Depending on the type of trade, gross retail margins vary from 15 to $45 \%$. Net profit margins, however, after deduction of operating costs, can be as low as $2 \%$ (for large scale trade in fast moving necessities). A difference of 0.2 percentage point then is a difference of $10 \%$ on net profit, at a given level of sales. On the whole, the result is consistent with previous results, though the evidence for asymmetry in the demand effect is now weaker than it was in the previous study in which asymmetry was allowed. ${ }^{18}$

The second step is to consider whether there are fluctuations of costs due to fluctuations of demand, and to eliminate such cyclical effects in a mark-up model. ${ }^{19}$ For this purpose we develop a mark-up model based on normal costs, which are defined as total percentage costs, decycled by eliminating fluctuations associated with growing or declining demand. The result is as follows:

$$
\begin{gathered}
\kappa_{i t}=\hat{\alpha}_{0}+\hat{\alpha}_{1 i} D_{i}-0.024 \dot{c}_{i t}^{+}-0.182 \dot{c}_{i t}^{-}+0.4 T_{t}, \quad R^{2}=0.967, \\
(0.030),(0.043) \quad(0.1)
\end{gathered}
$$

${ }^{17}$ Nooteboom (1985, p. 661).

${ }^{18} \mathrm{Cl}$. Nooteboom and Thurik (1985). The results of the two studies are not quite comparable, apart from a difference in the data set. In Nooteboom and Thurik (1985) an attempt was made to incorporate market share change in the variable of consumer spending growth. But we do not consider the method used sufficiently adequate to retain in the present study.

${ }^{19}$ Thurik and Kleijweg (1986) investigated the effect of short-term fluctuations of output on labour productivity in retailing. Actually, current volume of labour was modelled as a linear interpolation between actual volume in the previous period (year) and the volume of labour desired to match the current level of sales. This relation is based on a model presented in Nooteboom (1982), and on further applications in Thurik and Vollebregt (1984). See also Nooteboom (1983) for a model of retail productivity growth. 
where $D_{i}, i=1, \ldots, 15$, are dummy variables to represent cost differences between different types of shop. The estimates of the coefficients $\alpha_{0}$ and $x_{1 i}$ are of little interest here. $T_{t}$ is a linear time trend, assumed to be the same for all shop types.

The effect of demand growth $\left(\dot{c}^{+}\right)$is found to be non-significant, but the effect of demand decline $\left(\dot{c}^{-}\right)$is. The implication is, that when demand grows capacity is adjusted fairly quickly, but there is an adjustment lag (hoarding) when demand declines. A straightforward interpretation of this result is that it is easier to hire than to fire.

The asymmetry between growth and decline represents a refinement upon the previous study by Thurik and Kleijweg. According to the present result, a decline of sales by $1 \%$ yields a cost percentage which is about 0.2 percentage point higher than at a constant level of sales. Cost percentages vary from 15 to $35 \%$ of sales.

Normal costs are now defined as the trend value of costs,

$$
\bar{n}_{i t}=\hat{\alpha}_{0}+\hat{\alpha}_{1 i} D_{i}+0.4 T_{i},
$$

where $\bar{\kappa}=$ normal percentage costs.

The third step is to see whether demand growth has any significant effect on margins if we consider margins as a mark-up on normal rather than actual costs. The result is as follows:

$$
\begin{gathered}
\mu_{i t}=2.6+1.035 \bar{\kappa}_{i t}+9.40\left(1 / q_{i t}\right)+7.8\left(V_{i t} / Q_{i t}\right)+0.039 \dot{c}_{i t}^{+} \\
\quad(1.0)(0.034) \quad(1.50) \quad(1.1) \\
-0.075 c_{i i}^{-}-2.5 D_{g}, \quad R^{2}=0.981, \\
(0.038)(0.5)
\end{gathered}
$$

According to this result, demand growth or decline no longer has a significant effect (and the effect of a decline of demand has the wrong sign). This result does no more than illustrate the identification problem noted before: the use of normal costs necessarily leaves a smaller role for demand. Is it, then, just a matter of theoretical plausibility which model and view one takes?

The fourth step is to consider a partial adjustment in which, to the normal costs term, we add a term equal to the difference between actual and normal costs, with a coefficient that represents an adjustment process. The result is as follows:

$$
\begin{aligned}
\mu_{i t}= & 2.7+1.037 \bar{\kappa}_{i t}+0.47\left(\kappa_{i t}-\bar{\kappa}_{i t}\right)+9.20\left(1 / q_{i t}\right)+7.5\left(V_{i t} / Q_{i t}\right) \\
& (0.9)(0.030) \quad(0.08) \quad(1.30) \quad(1.0) \\
& +0.051 \dot{c}_{i t}^{+}+0.009 \dot{c}_{i t}^{-}-2.5 D_{g}, \quad R^{2}=0.985 \\
& (0.021)(0.037) \quad(0.5)
\end{aligned}
$$


According to this result, there is a partial adjustment to actual costs, with an adjustment coefficient of 0.47 . In other words, according to this view retailers may take normal costs as the basis, but then they do, to some extent, incorporate deviations of cost from its trend value. In this case, the results indicate that a demand effect persists in the case of growing demand, but not in the case of declining demand.

\section{Conclusions}

According to the orthodox theory of excess demand, price changes are determined by the level of excess demand. In other studies, which moved away from traditional theory, the price level is assumed to depend on the level of (excess) demand. Yet a third alternative is to consider the effect on the price level of a change in demand. The underlying idea is that businessmen seek growth of sales, and thereby set their prices at a lower level when either market share or total demand declines, in an attempt to maintain sales by striving for a larger market share. Conversely, when the market share increases, and the type of shop considered thus appears to be on the way up, in the 'wheel of retaiiing', or when total demand grows, whereby sales growth is assured, margins are widened to take more profits 'while the going is good'.

The present article takes this view as a maintained hypothesis, as part of a mark-up model of retail margins. Thus specified, the demand effect is significant and consistent, in the sense that it appears for demand growth as well as for declining demand, if actual costs are taken as the basis for the mark-up. When actual costs are replaced by normal costs, the demand effects disappear. When an allowance is made for a partial adjustment to the deviation of actual costs from their trend values, a partial adjustment emerges with a coefficient of about 0.5 . Under such partial adjustment, a significant demand effect persists, though it is not consistent, in the sense that it appears for demand growth but not for declining demand.

In other words: with a $50 \%$ adjustment to the deviation of actual costs from their trend value, there remains a demand effect in the form of a wider margin when demand is growing. We note that this result is associated with the finding that there is a significant deviation of costs from their trend value only when there is a decline of demand.

When this is taken into account, the results can be summarized as follows: growing demand yields only a small, and statistically insignificant decline of costs below trend value, and tends to yield a wider margin in addition to this cost advantage. Declining demand yields an excess of short-term costs over their trend value, and this excess is passed on only for about $50 \%$ in the form of a higher gross margin.

We conclude that the present study indicates that, in retailing, margins are 
set on the basis of a partial adjustment to deviations of actual from normal costs, and that there is an additional demand effect beyond cyclical effects on costs, at least when there is demand growth.

It would be worthwhile to replicate the study for retailing, on other sets of data. It might also be worthwhile to try and test the approach taken here in other sectors of services or manufacturing. These extensions will be pursued in future work.

\section{References}

Andrews, P.W.S. and E. Brunner, 1975, Studies in pricing (Macmillan, London).

Bode, B., J. Koerts and A.R. Thurik, 1986, On storekeepers' pricing behaviour, Journal of Retailing 62, 98-110.

Bucklin, L.P., 1972, Competition and evolution in the distributive trades (Prentice-Hall, New York).

Coutts, K., W. Godley and W. Nordhaus, 1978, Industrial pricing in the U.K. (Cambridge University Press, Cambridge).

Cyert, R.M. and J.G. March, 1963, A behavioral theory of the firm (Prentice-Hall, Englewood Cliffs, NJ).

Dreesmann, A.C.R., 1963, Evolutie en expansie, Parts I and II (Stenfert Kroese, Leiden).

Eichner, A.S., ed., 1979, A guide to post-Keynesian economics (Macmillan, London).

Godley, W.A.H. and W.D. Nordhaus, 1972, Pricing in the trade cycle, Economic Journal 82, 853-882.

Hall, R.L. and C.J. Hitch, 1939, Price theory and business behaviour, Oxford Economic Papers, $12-45$.

Hoeven, W.H.M. van der and A.R. Thurik, 1987, Pricing in the hotel and catering sector, De Economist 135, nr. 2.

Holdren, B.R., 1960, The structure of a retail market and the market behaviour of retail units (Prentice-Hall, Englewood Cliffs, NJ).

Kalecki, M., 1971, Selected essays on the dynamics of capitalist economy (Cambridge University Press, Cambridge).

Laidler, D. and M. Parkin, 1975, Inflation: A survey, The Economic Journal 85, Dec., 741-809.

McCallum, B.T., 1970, The effect demand on prices in British manufacturing: Another view, Review of Economic Studies 37, 147-156.

Maccini, L.J., 1978, The impact of demand and price expectations on the behaviour of prices, American Economic Review 68, March, 134-145.

McClelland, W.G.M., 1963, Studies in retailing (Basil Blackwell, Oxford).

McClelland, W.G.M., 1966, Costs and competition in retailing (Macmillan, New York).

Neild, R.R., 1963, Pricing and employment in the trade cycle (Cambridge University Press, Cambridge).

Nooteboom, B., 1980, Retailing: Applied analysis in the theory of the firm (Gieben, Uithoorn, Amsterdam).

Nooteboom, B., 1982, A new theory of retailing costs, European Economic Review 17, 163-186.

Nooteboom, B., 1983, Productivity growth in the grocery trade, Applied Economics 15, 649-664.

Nooteboom, B., 1985, A mark-up model of retail margins, Applied Economics 17, August, 647667.

Nooteboom, B. and A.R. Thurik, 1985, Retail margins during recession and growth, Economics Letters 17, 281-284.

Nooteboom, B., A.R., Thurik and J.A.C. Vollebregt, 1987, Do retail margins differ among European countries?, in: E. Kanyak, ed., Transitional retailing (De Gruyter, Berlin/New York, forthcoming).

Nordhaus, W.D., 1972, Recent developments in price dynamics, in: Otto Eckstein, ed., The econometrics of price determination (Board of Governors of the Federal Reserve System, Washington, DC). 
Nyström, H., 1970, Retail pricing: An integrated economic and psychological approach (Economic Research Institute, Stockholm).

Palamountain, J.C., 1955, The politics of distribution (Harvard University Press, Cambridge, MA).

Rushdy, F. and P.J. Lund, 1967, The effect of demand on prices in British manufacturing industry, Review of Economic Studies 34.

Smyth, R.L., 1967, A price-minus theory of cost?, Scottish Journal of Political Econom! it, June, 110-117.

Thurik, A.R. and A.J.M. Kleijweg, 1986, Procyclical retail labour productivity, Bulletin of Economic Research 38, 169-175.

Thurik, A.R. and J.A.C. Vollebregt, 1984, A generalized labour cost relation for French retailing, Annales de l'INSEE 53, 93-106.

Thurow, L.C., 1984, Dangerous currents (Vintage, New York).

Tucker, K.A. and B.S. Yamey, eds., 1973, Economics of retailing (Penguin Education, Harmondsworth).

Wood, A., 1975, A theory of profits (Cambridge University Press, Cambridge). 